\title{
Nano $\alpha$-FeOOH Modified Carbon Paste Electrode for Arsenic Determination in Natural Waters
}

\author{
Ruilin ZHANG ${ }^{1}$, Shijun HONG ${ }^{1}$, Dongxian ZHANG ${ }^{1}$, Shengjian LI $^{3}$, Zixi ZHAO ${ }^{3}$, \\ Huiping BAI ${ }^{2}$ *
}

\author{
${ }^{1}$ School of Forensic Medicine, Kunming Medical University, Kunming 650500, China \\ ${ }^{2}$ School of Material Science and Technology, Key Laboratory of Micro/nano Materials \& Technology; Yunnan University, \\ Kunming 650091, China \\ ${ }^{3}$ School of Chemical Science and Technology, Yunnan University, Kunming 650091, China
}

crossref http://dx.doi.org/10.5755/j01.ms.24.4.18499

Received 30 June 2017; accepted 04 January 2018

\begin{abstract}
A novel method for determination of inorganic arsenic in natural water, based on nano ferric hydroxides $(\mathrm{FeOOH})$ preconcentration and electrochemistry detection has been developed. As the nano $\alpha$-FeOOH could successfully act as the adsorbent and electrode matrix modifier, the method presents great potential in practical routine analysis of inorganic arsenic. With optimization of the experimental conditions, nano $\alpha$-FeOOH modified carbon paste electrode $(\alpha-$ FeOOH@CPE) was obtained by mixing $0.03 \mathrm{~g}$ of nano $\alpha-\mathrm{FeOOH}$ and $0.02 \mathrm{~g}$ graphite powder in $\mathrm{n}$-eicosane as an adhesive and then embedding them in a Teflon tube. Cyclic voltammetry, chronoamperometry and high resolution transmission electron microscopy were used to check and confirm the presence of nano $\alpha$-FeOOH on the carbon paste electrodes. According to the results, $\alpha-\mathrm{FeOOH} @ \mathrm{CPE}$ showed a considerably higher response to As(III) in comparison with the bare CPE, indicating the $\alpha-\mathrm{FeOOH}$ has well selective enrichment for As(III). The developed modified electrode showed a linear range of $1.0 \times 10^{-8} \sim 2.0 \times 10^{-5} \mathrm{~mol} \cdot \mathrm{L}^{-1}$ and detection limit of $5.0 \mathrm{nmol} \cdot \mathrm{L}^{-1}(\mathrm{~S} / \mathrm{N}=3)$. The newly prepared carbon paste electrode was successfully applied for As(III) determination in Yangzonghai Lake water with RSD of less than $3.6 \%(\mathrm{n}=3)$ and recovery in the range of $100.7 \sim 115.0 \%$.

Keywords: As(III), ferric hydroxides, carbon paste electrode, electrochemical sensor.
\end{abstract}

\section{INTRODUCTION}

Arsenic is a toxic non-metal element, which is widely distributed in the earth's crust, soil and water. Its concentration in water sources has lately been increased due to increasing industrial activity related to production of pigments, insecticides, herbicides and some other related materials. Unlawful drainage of by-products of these industrial processes constitutes the main road for As contamination of waters sources $[1,2]$. Therefore, arsenic pollution has become a global health threat due to its universality and toxicity. Particularly, inorganic arsenic and its compounds, being more toxic than organic arsenic species, are considered as a potent human carcinogen $[3,4]$.

In natural waters, the arsenic is mostly inorganic, i.e., arsenate and arsenite ions, denoted as $\mathrm{As}(\mathrm{V})$ and $\mathrm{As}(\mathrm{III})$ $[5,6]$. When $\mathrm{pH}$ of natural waters is near neutral, As(III) exists mainly in the form of neutral molecules, while As(V) exists mainly in the form of oxygen-containing anions, so electroneutrality As(III) is more difficult to adsorb by adsorbent than $\mathrm{As}(\mathrm{V})$. Arsenite [As(III)] is accepted as being more toxic than arsenate [As(V)] [7]. Hence, it is urgent to develop sensitive, rapid, and simple methods for analysis of trace inorganic arsenic.

At present, atomic absorption spectrometry (AAS) [5,8], hydride generation atomic fluorescence spectrometry (HGAFS) [9-11], and high performance

\footnotetext{
* Corresponding author. Tel.: +86-871-65036626

E-mail address: baihuiping@ynu.edu.cn (H. Bai)
}

liquid chromatography hyphenated to technique inductively coupled plasma mass spectrometry (HPLCICP-MS) [12-14] are the most effective methods for determination of inorganic arsenic. Although a large number of arsenic detection methods have been available, most methods only suitable for laboratory conditions, and the analysis results are sometimes not typical due to the physical and chemical properties of the sample may change during the collection process. In addition, the instruments used in these methods are expensive, complex, time-consuming, and even produce highly toxic $\mathrm{AsH}_{3}$.

Compared with the methods mentioned above, electrochemical analysis possesses of excellent characteristics like convenience in performance and simplicity in apparatus $[15,16]$. Jiang et al. reported a system using ultrathin $\mathrm{SnO}_{2}$ nanosheets with high reactive exposed (110) surface modified gold electrode for sensitive detection of $\mathrm{As}$ (III) by square wave anodic stripping voltammetry (SWASV) with a mild acid condition (pH 5.0) [17]. The modified electrode exhibits good performance in stripping determination of As(III). The LOD actually measured is $5 \mu \mathrm{g} \mathrm{L}^{-1}$. Zhou et al. developed an electrochemical method for direct determination of inorganic arsenic (As(III), As(V)), and total inorganic arsenic using an electrochemically etched gold wire microelectrode (Au-ME) by square wave anodic stripping voltammetry [18]. The determination of As(III) in $0.5 \mathrm{M} \mathrm{H}_{2} \mathrm{SO}_{4}$, the sensitivity increases 1.5 -fold to $6.8 \mu \mathrm{A} \mathrm{cm} \mathrm{ppb}^{-1}$ and the limit of detection (LOD) decreases 2.8 -fold to $2.6 \mathrm{ppb}$. 
Despite the above methods have lower detection limit and higher sensitivity, but there are still some problems, such as the electrode surface can be easily adsorbed with some analytes or intermediates and cannot be removed, the modifier is easy to fall off, which impacts the accuracy and stability of the detection result. Therefore, the development of new materials with environmentally friendly, easy to modify, good performance and easy to update the surface is the direction of researchers' efforts [19].

In nature, iron exists mainly in the form of oxides or hydroxyl oxides, which has a great variety, and content is quite rich on the earth's surface. In addition, iron has a strong affinity for arsenic [20]. Therefore, iron oxides and oxyhydroxides $(\mathrm{FeOOH})$ adsorption is the most widely used method to remove arsenic in water, rather than to ion exchange, membrane separation penetration, biological and electrical release arsenic and other methods, it is more effective and cheaper. Moreover, it has the advantage of easy operated and no environmental pollution effect. The study about iron oxides and oxyhydroxides such as goethite, hematite, amorphous iron hydroxide removal of arsenic has been reported [21-24].

Carbon paste electrodes (CPEs) have attracted attention as ion selective electrodes mainly due to their advantages over membrane electrodes such as renewability, stable response, low ohmic resistance, no need for internal solution [25-27]. The electrode containing adsorption materials tends to show selective behaviors. Besides, this modifying agent can preconcentrate the analyte in the electrode due to the high adsorption capacity of these materials.

Therefore, based on excellent adsorption properties of $\mathrm{FeOOH}$ on arsenic, using the regenerative and stability of $\mathrm{CPE}$, a $\alpha$-FeOOH@CPE has been developed for simple, sensitive and repeatable determination of arsenic ions in natural water. The prepared electrode showed very interesting analytical characteristics. To our knowledge, this is the first report on the application of nano $\alpha-\mathrm{FeOOH}$ as a recognition element in the carbon paste electrode composition and its using as a amperometric sensor for trace level As(III) determination.

\section{MATERIALS AND METHODS}

\subsection{Apparatus and instrumentation}

Electrochemical data were obtained with a threeelectrode system using CHI 660D electrochemical workstation (Shanghai $\mathrm{CH}$ Instruments Co., China) and 797 VA Computrace (Metrohm, Switzerland). A three electrode cell $(10 \mathrm{~mL})$ with the carbon paste electrodes modified with nano $\alpha-\mathrm{FeOOH}$ were used as a working electrode, a saturated calomel electrode (SCE) as reference electrode and a platinum wire electrode as counter electrode was used. All potentials were measured and reported versus SCE.

\subsection{Reagents and chemicals}

$\mathrm{NaAsO}_{2}$ were purchased from Xiya Reagent Co., Ltd. (Chendou, China); Graphite powder (APS, 2 15 $\mu \mathrm{m}$, $99.9995 \%$ ) were purchased from Sigma Aldrich (USA); $\mathrm{FeCl}_{3}$, Citric acid and $\mathrm{Na}_{3} \mathrm{C}_{6} \mathrm{H}_{5} \mathrm{O}_{7} \cdot 2 \mathrm{H}_{2} \mathrm{O}$ were purchased from Sinopharm Chemical Reagent Co., Ltd. (Shanghai, China); All chemicals were of analytical grade or better quality and used as received, and Milli-Q ultrapure water (18.25 M $\Omega$ ) was used throughout the experiments.

The stock solution of $\mathrm{As}(\mathrm{III})$ was prepared by dissolving appropriate amount of $\mathrm{NaAsO}_{2}$ in de-ionized water. The working standard solution was obtained by diluting the stock solution with de-ionized water.

\subsection{Synthesis of nano $\alpha$-FeOOH}

Nano $\alpha$-FeOOH was prepared by hydrothermal method under ambient temperature. Firstly, the $\mathrm{pH}$ of $2 \mathrm{~L}$ deionized water was adjusted to 8.6 through mixing $0.1 \mathrm{~mol} \mathrm{~L} \mathrm{NaHCO}_{3}$. Then $0.04 \mathrm{~mol} \mathrm{~L} \mathrm{~L}^{-1} \mathrm{FeCl}_{3}$ solution were added into above solution and stir well, which was sealed and kept at ambient temperature for $45 \mathrm{~d}$. The resulting yellow-brown product was centrifuged and washed with distilled water and absolute ethanol several times, and dried under vacuum at $60{ }^{\circ} \mathrm{C}$ overnight to obtain nano $\alpha-\mathrm{FeOOH}$.

\subsection{Preparation of the sensors}

For construction of the $\alpha-\mathrm{FeOOH} @ \mathrm{CPE}, \quad 0.02 \mathrm{~g}$ graphite was homogenized in a mortar with $0.03 \mathrm{~g}$ of powdered nano $\alpha-\mathrm{FeOOH}$ for $10 \mathrm{~min}$. Subsequently, $18 \mu \mathrm{L}$ n-eicosane was added to the graphite/FeOOH blend and mixed with a stainless steel spatula. The final paste was used to fill the bottom of teflon tube $(2.00 \mathrm{~mm}$ in diameter and $5.00 \mathrm{~mm}$ in depth) and then a copper wire $(5.00 \mathrm{~cm}$ in length) was inserted into the other end of the teflon tube. After drying at room temperature, the excess of solidified material was removed with the aid of a sheet of weigh paper. The electrode can be reused after each experiment by moving the electrode surface on a paper in order to rub out a thin layer of the electrode surface. The pure carbon paste electrodes (CPE) were prepared in the same way as above in the absence of imprinted polymer.

\subsection{Electroanalytical measurements}

The electrochemical characteristics of the $\alpha$ FeOOH@CPE were characterized by cyclic voltammetric and amperometric measurements. Cyclic voltammetric measurements were carried out in $10 \mathrm{~mL}$ of $0.1 \mathrm{~mol} \mathrm{~L}^{-1}$ citric acid/ sodium citrate buffer solution $(\mathrm{pH} 4.0)$ at room temperature from $-0.8 \mathrm{~V}$ to $+0.6 \mathrm{~V}$ with a scan rate of $100 \mathrm{mV} \mathrm{s}^{-1}$. The amperometric detection was based on the change in the current response $(\Delta \mathrm{i})$ before and after different concentrations of As(III) was added in acetic acid buffer solution and the potential for the determination of As(III) was $-0.4 \mathrm{~V}$.

\section{RESULTS AND DISCUSSION}

\subsection{Characterization of nano $\alpha-\mathrm{FeOOH}$}

Fig. 1 shows the TEM image of the prepared nano $\alpha$ $\mathrm{FeOOH}$ by hydrothermal method. The samples are both nano needle structures, whose sizes are uniform about with five micrometers in length and twenty nanometers in diameter. To investigate the structural details of $\alpha-\mathrm{FeOOH}$, 
HRTEM studies were performed taken from uncovered nano $\alpha-\mathrm{FeOOH}$ (Fig. 1 b).


b

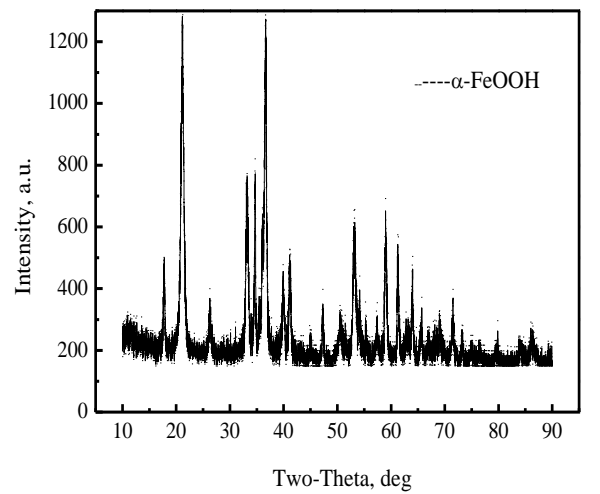

$\mathrm{c}$

Fig. 1. a-TEM; $b-$ HRTEM images of nano $\alpha-\mathrm{FeOOH}$, and inset of shows SAED pattern of nano $\alpha-\mathrm{FeOOH}$; c-XRD pattern of goethite

The well-resolved lattice planes illustrate that the nano $\alpha-\mathrm{FeOOH}$ is highly crystalline and structurally uniform. The measured interplanar spacing is about $0.398 \mathrm{~nm}$ that is consistent to the separation of $\{110\}$ planes of orthorhombic phase $\alpha-\mathrm{FeOOH}$. The presence of pattern spots in SAED pattern (shown in the inset of Fig. $1 \mathrm{~b}$ ) reveals the single crystalline nature of the selected area. Fig. $1 \mathrm{c}$ shows the XRD image of the prepared nano $\alpha$ $\mathrm{FeOOH}$, which illustrates that the formed $\mathrm{FeOOH}$ is six party most densely stacked structure, and there's no other impurity.

\subsection{Electrochemical characterization of a-FeOOH@CPE}

The electrochemical properties of the resulting $\alpha$ FeOOH@CPE (a) and CPE (b) were investigated by cyclic voltammetry in $10 \mathrm{~mL}$ of citric acid/ sodium citrate buffer solution ( $\mathrm{pH} 4.0$ ) with $6.0 \times 10^{-6} \mathrm{~mol} \mathrm{~L}^{-1} \mathrm{As}(\mathrm{III})$.

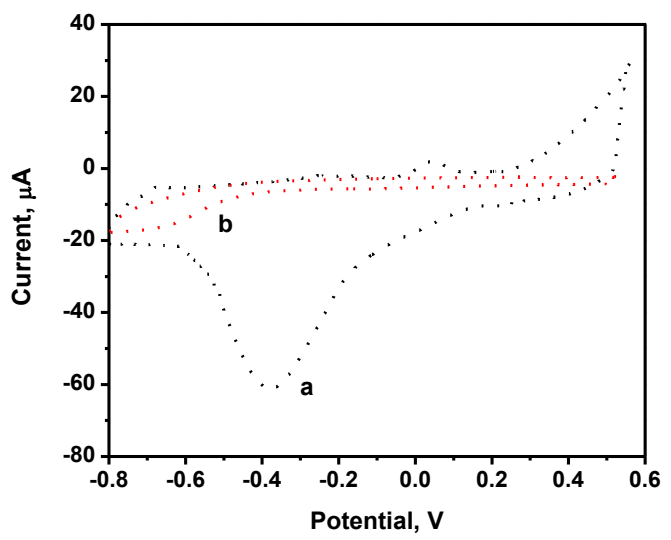

Fig. 2. Cyclic voltammograms of $a-\alpha-\mathrm{FeOOH} @ \mathrm{CPE} ; b-\mathrm{CPE}$, electrolyte: citric acid/ sodium citrate buffer solution $\left(0.1 \mathrm{~mol} \mathrm{~L}^{-1}, \mathrm{pH} 4.0\right)$ and $6.0 \mu \mathrm{mol} \mathrm{L}^{-1} \mathrm{As}(\mathrm{III})$, scan rate: $100 \mathrm{mV} \mathrm{s}^{-1}$

It can be seen from Fig. 2 that an obvious reduction peak $(\varphi=-0.4 \mathrm{~V})$ was observed for $\alpha-\mathrm{FeOOH} @ \mathrm{CPE}$ (curve a), but CPE did not, while the solution containing $6.0 \times 10^{-6} \mathrm{~mol} \mathrm{~L}^{-1} \mathrm{As}(\mathrm{III})$. Which is caused by the reduction of $\mathrm{As}(\mathrm{III})$ to $\mathrm{As}(0)$ in this process [28]. This result demonstrates that $\mathrm{As}(\mathrm{III})$ was reduced only in the $\alpha$ FeOOH@CPE. The reason might be $\mathrm{FeOOH}$ is a semiconducting material with good conductivity and it has certain catalytic activity, which accelerate the electron transfer between electrodes and solutions, and enhance the amperometric response to As (III).

\subsection{Optimization of the conditions for a-FeOOH@CPE preparation}

In order to find the optimum composition for the $\alpha$ FeOOH@CPE, the effects of the component of the electrodes including $\mathrm{FeOOH}$ and graphite powder on the $\alpha$ FeOOH@CPE behavior were investigated.

The $\alpha$-FeOOH@CPE was prepared with a fixed amount of graphite $(0.02 \mathrm{~g})$ and different amounts of nano $\alpha$-FeOOH $(0.01,0.02,0.03,0.04$ and $0.06 \mathrm{~g})$. The obtained results are shown in Fig. 3 a. It is clear that the maximum response of the prepared sensor appears in the nano $\alpha$ FeOOH amount of $0.03 \mathrm{~g}$. The $\alpha-\mathrm{FeOOH} @ \mathrm{CPE}$ response increased with the increment of the nano $\alpha-\mathrm{FeOOH}$, the possible reason was that $\alpha-\mathrm{FeOOH}$ can adsorption more As (III) on the electrode surface. However, increasing the $\alpha$ FeOOH above a threshold amount led to a decrease in the response of the prepared sensor, most probably due to the conductivity decrease on the electrode surface [29].

The effect of the amount of graphite powder was also investigated. As presented in Fig. 3 b, the optimum amount of graphite powder was $0.02 \mathrm{~g}$. As the amount of graphite powder increases, the initial increase in the response can be related to the enhancement in the electron transferring capability of the electrode. And, subsequent signal 
decrease may be due to decreasing the $\alpha$-FeOOH content on the electrode surface resulting in the reduction of adsorption capacity and its response [30,31]. So, $0.02 \mathrm{~g}$ graphite and $0.03 \mathrm{~g}$ nano $\alpha-\mathrm{FeOOH}$ as the optimum composition were used in the following investigation.

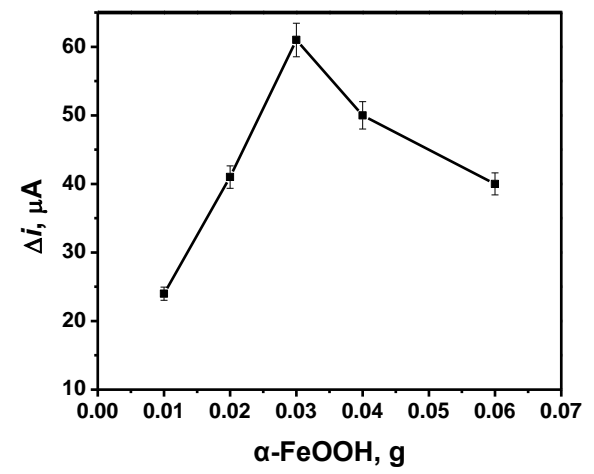

a

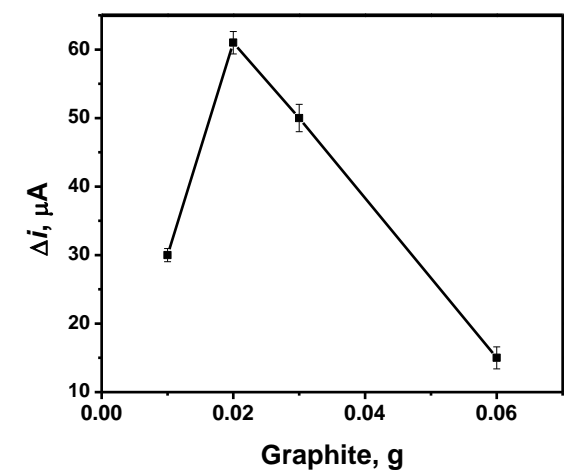

$\mathrm{b}$

Fig. 3. Effect of the amounts of $a-\alpha-\mathrm{FeOOH} ; \mathrm{b}-$ graphite powder on the $\alpha-\mathrm{FeOOH} @ \mathrm{CPE}$ response in citric acid/ sodium citrate buffer solution ( $\mathrm{pH} 4.0)$ containing $6.0 \mu \mathrm{mol} \cdot \mathrm{L}^{-1} \mathrm{As}(\mathrm{III})$ at the potential of $-0.4 \mathrm{~V}$

\subsection{Optimization of determination conditions}

In order to improve the sensitivity of the $\alpha$ FeOOH@CPE, determination conditions like the composition and $\mathrm{pH}$ of the electrolyte solution as well as the applied potential was optimized. $0.1 \mathrm{~mol} \mathrm{~L}^{-1}$ acetic acid buffer solution ( $\mathrm{pH} 4.0$ ), $0.1 \mathrm{~mol} \mathrm{\textrm {L } ^ { - 1 }}$ citric acid/ sodium citrate buffer solution $(\mathrm{pH} 4.0)$ and $1 / 15 \mathrm{~mol} \mathrm{~L}^{-1}$ phosphate buffer solution ( $\mathrm{pH} 4.0)$ as supporting electrolytes were studied using amperometric responses containing $6.0 \times 10^{-6} \mathrm{~mol} \mathrm{~L}^{-1}$ As (III). Preliminary results show it has the strongest current response in the citric acid/ sodium citrate buffer solution. On this basis, we studied the effect of the citric acid/ sodium citrate buffer solution $\mathrm{pH}$ on current response. The results are shown in Fig. 4. The experimental results indicated that arsenic ions exhibit a sensitive electrochemical response in the citric acid/sodium citrate buffer solution ( $\mathrm{pH} 4.0)$.

Therefore, $\mathrm{pH} 4.0$ citric acid/ sodium citrate buffer solution was used for the determination of As(III) to achieve higher sensitivity.

The effect of applied potential on the $\alpha-\mathrm{FeOOH} @ \mathrm{CPE}$ response was studied in citric acid/ sodium citrate buffer solution ( $\mathrm{pH} 4.0$ ) containing $6.0 \times 10^{-6} \mathrm{~mol} \cdot \mathrm{L}^{-1} \mathrm{As}(\mathrm{III})$. As can be seen from Fig. 5, the response current of the increases as the potential decrease from 0.3 to $-0.8 \mathrm{~V}$, and maintains its maximum value in the potential range of -0.4 to $-0.8 \mathrm{~V}$. To avoid interference at high negative applied potential, a potential of $-0.4 \mathrm{~V}$ (vs. SCE) was selected as the applied potential for amperometric measurements.

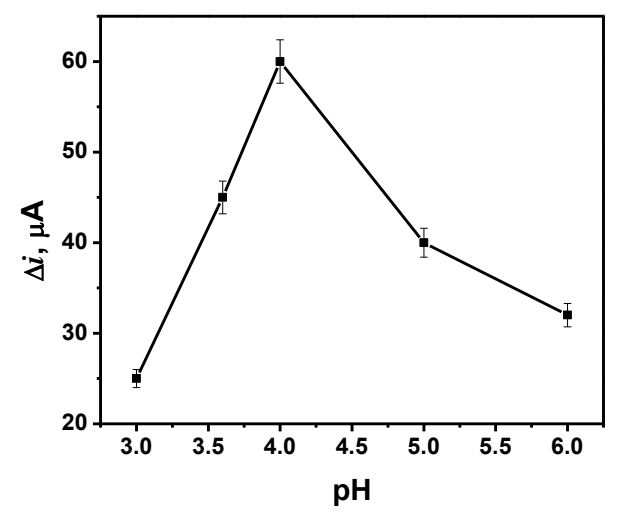

Fig. 4. Effect of $\mathrm{pH}$ on the $\alpha-\mathrm{FeOOH} @ \mathrm{CPE}$ response in buffer solutions containing $6.0 \mu \mathrm{mol} \cdot \mathrm{L}^{-1} \mathrm{As}(\mathrm{III})$ at the potential of $-0.4 \mathrm{~V}$.

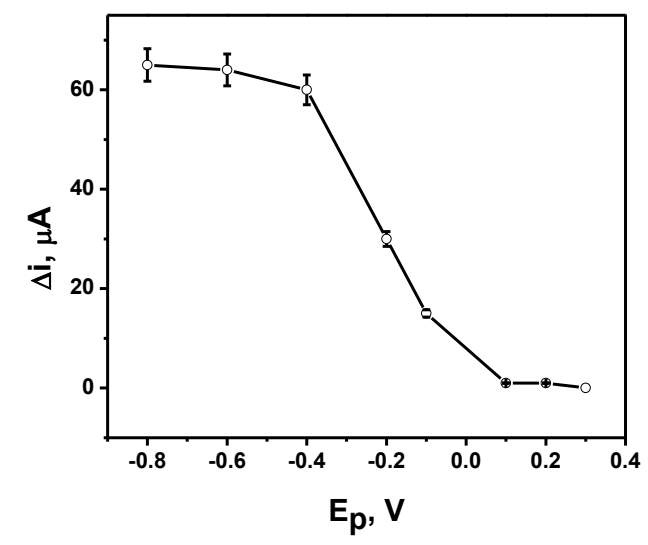

Fig. 5. Effect of the applied potential on the $\boldsymbol{\alpha}-\mathrm{FeOOH} @ \mathrm{CPE}$ response in citric acid/ sodium citrate buffer solution ( $\mathrm{pH} 4.0$ ) containing $6.0 \mu \mathrm{mol} \cdot \mathrm{L}^{-1} \mathrm{As}(\mathrm{III})$

\subsection{Amperometric i-t curve}

The affinity of the $\alpha-\mathrm{FeOOH} @ \mathrm{CPE}$, and bare CPE to $\mathrm{As}(\mathrm{III})$ was investigated with a concentration range from $1.0 \times 10^{-8} \mathrm{~mol} \cdot \mathrm{L}^{-1}$ to $2.0 \times 10^{-5} \mathrm{~mol} \cdot \mathrm{L}^{-1}$ by amperometric $i-t$ curve at the potential of $-0.4 \mathrm{~V}$. Each concentration change induced a current change. As shown in Fig. 6, the amperometric currents of the $\alpha-\mathrm{FeOOH} @ \mathrm{CPE}$ increased with the increment of As(III) concentration.

And the current can be stabilized in 100 seconds, indicating that the electrode reaches the adsorption equilibrium. Noticeably, the sensitivity of $\alpha-\mathrm{FeOOH} @ \mathrm{CPE}$ is significantly greater than that of the bare $\mathrm{CPE}$, indicating that the specific adsorption performance of $\alpha-\mathrm{FeOOH}$ can enhance amperometric response to $\mathrm{As}(\mathrm{III})$. Inset in Fig. 6 shows a linear relation between the response currents and As(III) concentrations range over $1.0 \times 10^{-8} \sim 2.0 \times 10^{-5} \mathrm{~mol} \cdot \mathrm{L}^{-1}$, and the linear regression equation was as follows:

$\Delta i(\mu \mathrm{A})=6.5682 c+21.898\left(\mu \mathrm{mol} \cdot \mathrm{L}^{-1}\right)(\mathrm{r}=0.9992)$ 
The limit of detection of the $\alpha-\mathrm{FeOOH} @ \mathrm{CPE}$, which is defined as the lowest concentration of As(III) producing a peak current 3 times higher than the standard deviation of 9 blank measurements, is found to be $5.0 \times 10^{-9} \mathrm{~mol} \cdot \mathrm{L}^{-1}$ (or $0.375 \mu \mathrm{g} \mathrm{L}^{-1}$ ), well below the $10 \mu \mathrm{g} \mathrm{L}^{-1}$ maximum allowed limit required by WHO [32].

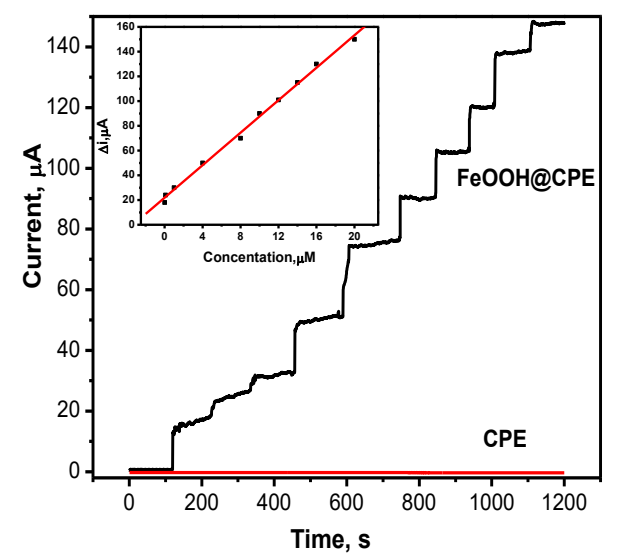

Fig. 6. Typical current response i-t curve of $\alpha-\mathrm{FeOOH} @ \mathrm{CPE}$ and CPE with increasing addition of As(III) in citric acid/ sodium citrate buffer solution ( $\mathrm{pH} 4.0)$. Applied potential: $-0.4 \mathrm{~V}$. Concentration $\left(\mu \mathrm{mol} \cdot \mathrm{L}^{-1}\right)$ of $\mathrm{As}(\mathrm{III})$ for each detection: $0.01,0.1,1.0,4.0,8.0,10.0,12.0,14.0$, 16.0, 20.0. Inset is the calibration curve of FeOOH@CPE

\subsection{Selectivity, repeatability and stability}

To further investigate the selectivity performance of the $\alpha$-FeOOH@CPE, the response currents of the $\alpha$ FeOOH@CPE to $1.0 \times 10^{-6} \mathrm{~mol} \cdot \mathrm{L}^{-1} \mathrm{As}(\mathrm{III})$ and different concentrations of other referencing ions were detected by amperometric responses in citric acid/ sodium citrate buffer solution. As you can see from Table 1, a vast majority of metal ions show no significantly interference in the determination of $\mathrm{As}$ (III) including $\mathrm{Cu}^{2+}, \mathrm{Zn}^{2+}, \mathrm{Al}^{3+}$, $\mathrm{Mg}^{2+}, \mathrm{Fe}^{3+}$ at a concentration 10 times as much as that of the target analyte. 20-fold excess of $\mathrm{NO}_{3}{ }^{-}, \mathrm{PO}_{4}{ }^{3-}, \mathrm{SO}_{4}{ }^{2-}, \mathrm{Cl}^{-}$ were found no interference in the detection of As(III). Therefore, the $\alpha-\mathrm{FeOOH} @ \mathrm{CPE}$ has a high selectivity to arsenic ions.

Table 1. The response current $(\Delta i)$ of $\alpha-\mathrm{FeOOH} @ \mathrm{CPE}$ to different metal ions

\begin{tabular}{|c|c|c|c|c|c|}
\hline Ions & $\begin{array}{c}\text { Concentration, } \\
\mu \mathrm{mol} \cdot \mathrm{L}^{-1}\end{array}$ & $\Delta i$ & Ions & $\begin{array}{c}\text { Concentration, } \\
\mu \mathrm{mol} \cdot \mathrm{L}^{-1}\end{array}$ & $\Delta i$ \\
\hline $\mathrm{As}(\mathrm{III})$ & 1.0 & 30.16 & $\mathrm{Cu}^{2+}$ & 10.0 & 5.50 \\
\hline $\mathrm{Zn}^{2+}$ & 10.0 & 0.00 & $\mathrm{PO}_{4}^{3-}$ & 20.0 & 0.00 \\
\hline $\mathrm{Mg}^{2+}$ & 10.0 & 0.00 & $\mathrm{NO}_{3}-$ & 20.0 & 0.00 \\
\hline $\mathrm{Fe}^{3+}$ & 10.0 & 2.60 & $\mathrm{SO}_{4}^{2-}$ & 20.0 & 0.00 \\
\hline $\mathrm{Al}^{3+}$ & 10.0 & 0.00 & $\mathrm{Cl}^{-}$ & 20.0 & 0.00 \\
\hline
\end{tabular}

To investigate the reproducibility of the electrochemical method, three $\alpha-\mathrm{FeOOH} @ \mathrm{CPE}$ were prepared under the identical experimental conditions to determine $6.0 \times 10^{-6} \mathrm{~mol} \cdot \mathrm{L}^{-1}$ As (III). The calculated RSD of the peak currents obtained with different sensors was $7.0 \%$. Moreover, three separate determinations of As(III) by the same electrode resulted in an $\mathrm{RSD}=4.2 \%(\mathrm{n}=3)$. The stability of $\alpha-\mathrm{FeOOH} @ \mathrm{CPE}$ for determination of
$6.0 \times 10^{-6} \mathrm{~mol} \mathrm{~L}^{-1}$ As (III) were also assessed. The results show that the electrode can hold more than $87 \%$ of its original current response after used more than 60 times. All these results can prove that the proposed $\alpha$ FeOOH@CPE has excellent storage stability and reproducibility.

\subsection{Sample analysis}

The obtained $\alpha$-FeOOH@CPE was validated by analyzing the arsenic content in the natural water samples from Yangzonghai Lake. The results presented in Table 2 suggest that the recoveries of As(III), via the standard addition method, are in the range of 100.7 115.0\%, and the reproducibility of the procedure, expressed as RSD, is less than $3.6 \%$, which indicates the method could be accurate for arsenic analysis in real water samples.

Table 2. Determination of As(III) in Yangzonghai water samples by $\alpha-\mathrm{FeOOH} @ \mathrm{CPE}(n=3)$

\begin{tabular}{|c|c|c|c|c|}
\hline Samples & $\begin{array}{c}\text { Added, } \\
\mu \mathrm{mol} \cdot \mathrm{L}^{-1}\end{array}$ & $\begin{array}{c}\text { Found, } \\
\mu \mathrm{mol} \cdot \mathrm{L}^{-1}\end{array}$ & RSD, \% & Recover, \% \\
\hline \multirow{4}{*}{$\begin{array}{c}\text { Yang } \\
\text { zonghai } \\
\text { water }\end{array}$} & 0.00 & N.D. ${ }^{a}$ & & \\
\hline & 1.00 & 1.15 & 3.6 & 115.0 \\
\hline & 8.00 & 8.24 & 2.9 & 103.0 \\
\hline & 14.00 & 14.10 & 2.4 & 100.7 \\
\hline
\end{tabular}

\section{CONCLUSIONS}

In this paper, a novel electrochemical sensor has been constructed for detecting As(III) in natural waters using nano $\alpha-\mathrm{FeOOH}$ modified carbon paste electrode. Nano needle $\alpha-\mathrm{FeOOH}$ was synthesized by the simplest hydrothermal method under ambient temperature. Iron has a strong affinity for arsenic. Thus, nano $\alpha$-FeOOH played the role of a pre-concentrator to exhibit high selectivity as well as a low detection limit. As a result, the developed sensor showed high selectivity and high sensitivity. With the advantages of easily surface regenerate, simple preparation and low cost, the modified electrodes have great space for development in practical applications area.

\section{Acknowledgments}

This work was financially supported by the Science Research Foundation of Yunnan Province Education Department (No.2017ZZX231), Natural Science Fund of Yunnan Province (No.2017FB012) and Kunming Medical University Creative Group Programme (No.CXTD201604).

\section{REFERENCES}

1. Carrera, P., Espinoza-Montero, P.J., Fernández, L., Romero, H., Alvarado, J. Electrochemical Determination of Arsenic in Natural Waters Using Carbon Fiber Ultramicroelectrodes Modified with Gold Nanoparticles Talanta 166 (5) 2017: pp. 198-206.

https://doi.org/10.1016/j.talanta.2017.01.056

2. Zhang, W.H., Qi, Y.H., Qin, D.Y., Liu, J.X., Mao, X.F., Chen, G.Y., Wei, C., QianY.Z. Determination of Inorganic Arsenic in Algae using Bromine Halogenations and on-line Nonpolar Solid Phase Extraction Followed by Hydride Generation Atomic Fluorescence Spectrometry Talanta 170 (8) 2017: pp. $152-157$. 
https://doi.org/10.1016/j.talanta.2017.04.001

3. Choong, T.S.Y., Chuah, T.G., Robiah, Y., Koay, F.L.G., Azni, I. Arsenic Toxicity, Health Hazards and Removal Techniques from Water: An Overview Desalination $217(1-3)$ 2007: pp. 139-166.

https://doi.org/10.1016/j.desal.2007.01.015

4. Karagas, M.R., Punshon, T., Sayarath, V., Jackson, B.P., Folt, C.L., Cottingham, K.L. Association of Rice and RiceProduct Consumption with Arsenic Exposure Early in Life JAMA Pediatrics 170 (12) 2016: pp. 609-616. https://doi.10.1001/jamapediatrics.2016.0120.

5. Wang, Q., Yu, Z.N., $\quad$ Lan, J., Liu, A.F., Tian, Y. Bifunctional Magnesium Oxide Crystal Successively as Adsorbent and Matrix Modifier for Preconcentration and Determination of Arsenic by Graphite Furnace Atomic Absorption Spectrometry Microchemical Journal 133 (7) 2017: pp. $412-416$.

https://doi.10.1001/jamapediatrics.2016.0120

6. Cui, J., Shi, J., Jiang, G., Jing, C. Arsenic Levels and Speciation from Ingestion Exposures to Biomarkers in Shanxi, China: Implications for Human Health Environmental Science \& Technology 47 (10) 2013: pp. 5419-5424.

https://doi. 10.1021/es400129s

7. Chen, C.J., Wang, C.J. Ecological Correlation between Arsenic Level in Well Water and Age-adjusted Mortality from Malignant Neoplasms Cancer Research 50 1990: pp. $5470-5474$.

https://doi. Published September 1990

8. Shirani, M., Semnani, A., Habibollahi, S., Haddadi, H. Ultrasound-assisted, Ionic Liquidlinked, Dual-magnetic Multiwall Carbon Nanotube Microextraction Combined with Electrothermal Atomic Absorption Spectrometry for Simultaneous Determination of Cadmium and Arsenic in Food Samples Journal of Analytical Atomic Spectrometry 30 (5) 2015: pp. 1057-1063.

https://doi. 10.1039/C4JA00481G

9. Luo, J., Xu, F.J., Hu, J., Lin, P., Tu, J.P., Wu, X., Hou, X.D. Preconcentration on Metal Organic Framework UiO-66 for Slurry Sampling Hydride Generation-atomic Fluorescence Spectrometric Determination of Ultratrace Arsenic Microchemical Journal 133 (7) 2017: pp. $441-447$. https://doi.org/10.1016/j.microc.2017.03.056

10. Zhou, Q.X., Zheng, Z.W., Xiao, J.P., Fan, H.L. Sensitive Determination of $\mathrm{As}(\mathrm{III})$ and $\mathrm{As}(\mathrm{V})$ by Magnetic Solid Phase Extraction with Fe@polyethyleneimine in Combination with Hydride Generation Atomic Fluorescence Spectrometry Talanta 156 (8) 2016: pp. 196-203. https://doi.org/10.1016/j.talanta.2016.05.024

11. Yuan, C.G., Zhang, K., Wang, Z., Jiang, G. Rapid Analysis of Volatile Arsenic Species Released from Lake Sediment by a Packed Cotton Column Coupled with Atomic Fluorescence Spectrometry Journal of Analytical Atomic Spectrometry 25 (10) 2010: pp. 1605-1611. https://doi.10.1039/C0JA00005A

12. Hsieh, Y.J., Jiang, S.J. Application of HPLC-ICP-MS and HPLC-ESI-MS Procedures for Arsenic Speciation in Sea Weeds Journal of Agricultural and Food Chemistry 60 (9) 2012: pp. $2083-2089$. https://doi. 10.1021/jf204595d

13. Maher, W.A., Ellwood, M.J., Krikowa, F., Raber, G., Foster, S. Measurement of Arsenic Species in Environmental, Biological Fluids and Food Samples by
HPLC-ICPMS and HPLC-HG-AFS Journal of Analytical Atomic Spectrometry 30 (10) 2015: pp. 2129-2183. https://doi. 10.1039/C5JA00155B

14. Jia, X.Y., Gong, D.R., Wang, J.N., Huang, F.Y., Duan, T.C., Zhang, X. Arsenic Speciation in Environmental Waters by Anew Specific Phosphine Modified Polymer Microsphere Pre-concentration and HPLC-ICP-MS Determination Talanta 160 (11) 2016: pp. $437-443$. https://doi.org/10.1016/j.talanta.2016.07.050

15. Antonova, S., Zakharova, E. Inorganic Arsenic Speciation by Electroanalysis. From Laboratory to Field Conditions: a Mini-review Electrochemistry Communications 70 (9) 2016: pp. $33-38$. https://doi.org/10.1016/j.elecom.2016.06.011

16. Cavicchioli, A., La-Scalea, M.A., Gutz, I.G.R. Analysis and Speciation of Traces of Arsenic in Environmental Food and Industrial Samples by Voltammetry: a Review Electroanalysis $16(9)$ 2004: pp. 697-711. https://doi.org/10.1002/elan.200302936

17. Jiang, T.J., Guo, Z., Liu, J.H., Huang, X.J. Gold Electrode Modified with Ultrathin $\mathrm{SnO}_{2}$ Nanosheets with High Reactive Exposed Surface for Electrochemical Sensing of As(III) Electrochimica Acta 191 (10) 2016: pp. $142-148$. https://doi.org/10.1016/j.electacta.2015.12.196

18. Zhou, C., Yang, M., Li, S.S., Jiang, T.J., Liu, J.H., Huang, X.J., Chen, X. Electrochemically Etched Gold Wire Microelectrode for the Determination of Inorganic Arsenic Electrochimica Acta 231 (3) 2017: pp. 238-246. https://doi.org/10.1016/j.electacta.2017.01.184

19. Liu, Z.G. Study on Au Microwire Electrode for the Electrochemical Detection of Arsenic in Groundwater. Doctoral Thesis, University of Science and Technology of China, Beijing, 2015: pp. 5-6.

20. Manning, B., Fendorf, S., Goldberg, S. Surface Structures and Stability of Arsenic(III) on Goethite: Spectroscopic Evidence for Inner-Sphere Complexes Environmental Science \& Technology 32 (16) 1998: pp. 2383-2388. https://doi. 10.1021/es9802201

21. Chen, J., Wang, S.X., Zhang, S., Yang, X.J., Huang, Z.J., Wang, C., Wei, Q.Y., Zhang, G.L. Arsenic Pollution and its Treatment in Yangzonghai Lake in China: In situ remediation Ecotoxicology and Environmental Safety 122 (12) 2015: pp. $178-185$. https://doi.org/10.1016/j.ecoenv.2015.07.032

22. Ozola, R., Krauklis, A., Leitietis, M., Burlakovs, J., Vircava, I., Ansone-Bertina, L., Bhatnagar, A., Klavins, M. FeOOH-Modified Clay Sorbents for Arsenic Removal from Aqueous Solutions Environmental Technology \& Innovation In Press https://doi.org/10.1016/j.eti.2016.06.003

23. Faria, C.S.M., Rosemberg, R.S., Bomfeti, C.A., Monteiro, D.S., $\quad$ Barbosa, F., $\quad$ Oliveira, L.C.A., Rodriguez, M., Pereira, M.C., Rodrigues, J.L. Arsenic Removal from Contaminated Water by Ultrafine $\delta$-FeOOH Adsorbents Chemical Engineering Journal 237 (2) 2013: pp. $47-54$. https://doi.org/10.1016/j.cej.2013.10.006

24. Zhang, J.S., Stanforth, R.S., Pehkonen, S.O. Effect of Replacing a Hydroxyl Group with a Methyl Group on Arsenic $(V)$ Species Adsorption on Goethite $(\alpha-\mathrm{FeOOH})$ Journal of Colloid and Interface Science $306(1)$ 2007: pp. 16-21. https://doi.org/10.1016/j.jcis.2006.10.004 
25. Niknezhadi, A., Nezamzadeh-Ejhieh, A. A Novel and Sensitive Carbon Paste Electrode with Clinoptilolite Nanoparticles Containing Hexadecyltrimethyl Ammonium Surfactant and Dithizone for the Voltammetric Determination of Sn(II) Journal of Colloid and Interface Science 501 (9) 2017: pp. 321-329.

https://doi.org/10.1016/j.jcis.2017.04.068

26. Khaleghi, F., Irai, A.E., Sadeghi, R., Gupta, V.K., Wen, Y.P. A Fast Strategy for Determination of Vitamin B9 in Food and Pharmaceutical Samples Using an Ionic Liquidmodified Nanostructure Voltammetric Sensor Sensors 16 (6) 2016: pp. 747-759. https://doi.org/10.3390/s16060747

27. Akhoundian, M., Rüter, A., Shinde, S. Ultratrace Detection of Histamine Using a Molecularly-imprinted Polymer-based Voltammetric Sensor Sensors 17 (6) 2017: pp. 645 -655. https://doi:10.3390/s17030645

28. Lan, Y.C., Luo, H.J., Wang, C. Determination of Arsenite in Water by Anodic Stripping Voltammetry Using $\mathrm{Au}-\mathrm{Pd}$ Bimetallic Nanoparticles Modified Glassy Carbon Electrode Journal of Instrumental Analysis 31 (4) 2012: pp. $459-463$.

https://doi.10.3969/j.issn.1004-4957.2012.04.016
29. Bahrami, A., Besharati-Seidani, A., Abbaspour, A., Shamsipur, M. A Highly Selective Voltammetric Sensor for Sub-nanomolar Detection of Lead Ions Using a Carbon Paste Electrode Impregnated with Novel Ion Imprinted Polymeric Nanobeads Electrochimica Acta 118 (1) 2014: pp. 92-99. https://doi.org/10.1016/j.electacta.2013.11.180

30. Song, B., Zhou, Y.S., Jin, H., Jing, T., Zhou, T.T., Hao, Q.L., Zhou, Y.K., Mei, S.R., Lee, Y. Selective and Sensitive Determination of Erythromycin in Honey and Dairy Products by Molecularly Imprinted Polymers Based Electrochemical Sensor Microchemical Journal 116 (9) 2014: pp. $183-190$ https://doi.org/10.1016/j.microc.2014.05.010

31. Alizadeh, T., Ganjali, M.R., Zare, M., Norouzi, $P$. Selective Determination of Chloramphenicol at Trace Level in Milk Samples by the Electrode Modified with Molecularly Imprinted Polymer Food Chemistry 130 (4) 2012: pp. $1108-1114$. https://doi.org/10.1016/j.foodchem.2011.08.016

32. WHO Arsenic Compounds, Environmental Health Criteria 224, 2nd ed., World Health Organisation, Geneva, 2001. 